\title{
Xyloglucan Based Nasal in situ Gel Formulation of Mirtazapine for Treatment of Depression
}

\author{
Wadetwar Rita Naresh, Deshmukh Vaibhav Dilip, Kanojiya Pranita Sunil \\ Department of Pharmaceutical Sciences, Rashtrasant Tukadoji Maharaj Nagpur University, Amravati Road, \\ Nagpur, Maharashtra, INDIA.
}

\begin{abstract}
Objectives: The objective of the present work was formulation of thermosensitive mucoadhesive in situ nasal gel of Mirtazapine for depression. The nasal route would overcome the first-pass effect and would enhance its efficacy. Methods: The thermally triggered in situ nasal gel was prepared by cold method using Poloxamer 407 and Xyloglucan. Formulation batches of in situgel were prepared by using $3^{2}$ full factorial design. The in situ gel was evaluated for gelling temperature, \% drug content, ex vivo permeation study and pharmacodynamic study. Results: The differential scanning calorimetry (DSC) and Fourier Transform Infrared (FTIR) spectroscopy of drug and physical mixture showed compatibility. Drug content and gelling temperature of optimized batch was found to be $85.22-95.92 \%$ and $30-35^{\circ} \mathrm{C}$ respectively. Ex vivo permeation of optimized formulation F4 was found to be $91.89 \%$. Pharmacodynamic study was performed using despair forced swim test and locomotor activity on mice and it was found that in situ nasal gel of Mirtazapine was more effective than that of the marketed formulation. Stability studies revealed that the optimized formulation was stable. Conclusion: The prepared in situ nasal gel of Mirtazapine enhanced the residence time in the nostrils and enhanced the therapeutic efficacy by avoidance of first-pass metabolism.

Key words: In situ nasal gel, Poloxamer 407, Xyloglucan, Mirtazapine, Mucoadhesive, Depression, Gelling temperature.

Key message: The novel formulation of Mirtazapine in situ nasal gel containing Xyloglucan possess high mucoadhesive strength for increasing the nasal residence time required for therapeutic effect. It has sufficient viscosity to be poured as nasal drop and then get gelled at nasal physiological temperature.
\end{abstract}

\section{INTRODUCTION}

Depression will be the $2^{\text {nd }}$ major cause of morbidity of the next decade in the world according to the report of WHO. Depression covers children, teenagers and adult patients. It is one of the annoying and unidentified disorder. ${ }^{1}$

Depression is a mental disorder and represents manifestations such as depressed mood, low energy, disturbed sleep, loss of appetite, decrease in interest or pleasure, feelings of guilt or low self-esteem, weak concentration and anxiety. ${ }^{2}$

The symptoms may become chronic and can lead to a fall in individual's responsibilities. It can also lead to suicide. Approximately
1 million of the population dies by committing suicide every year. ${ }^{3}$

Treating mental disorders is a challenging task due to several hurdles in the delivery of drugs. There are less systematic approaches to deliver them. If the potent drug crosses the blood brain barrier (BBB), then it reaches the CNS and elicits its response. Therefore, crossing of the drug through $\mathrm{BBB}$ is a prerequisite for effective treatment of mental disorder. ${ }^{4,5}$

Intranasal delivery has recently gained popularity for topical, systemic as well as brain targeting. It offers efficient drug delivery by avoiding extensive hepatic first pass metabolism, stringent acidic condition
Submission Date: 20-11-2019; Revision Date: 27-02-2020; Accepted Date: 30-04-2020

\section{DOI: 10.5530/ijper.54.2s.77}

Correspondence:

Dr. Rita N Wadetwar Assistant Professor (Pharmaceutics), Department of Pharmaceutical Sciences, Rashtrasant Tukaoji Maharaj, Nagpur University, Amravati Road,

Nagpur-440 033 Maharashtra, INDIA.

Phone: +91 8007995551 E-mail: rnwadetwar@gmail. com



www.ijper.org 
inside the gastrointestinal tract, better pharmacokinetic parameters for the lipophilic drugs, targeted drug delivery to brain through the olfactory pathway of nose. Being non-invasive, intranasal formulation has more acceptability by patients. ${ }^{6}$

Mirtazapine, a tetracyclic antidepressant, is used in the treatment of major depressive disorder, anxiety, insomnia, nausea and vomiting and to produce weight gain when desirable. The drug is extensively metabolized in the liver via CYP1A2, CYP2D6, CYP3A4 and so has a low oral bioavailability of $50 \%$ and the presence of food in the stomach reduces the absorption of the drug. Under these conditions, intranasal delivery appears to be an attractive alternative. ${ }^{7}$

Poloxamer 407 is one of the best thermosensitive gelling polymer. Chemically it contains repeating units of hydrophilic polyethylene oxide (PEO) and the lipophilic polypropylene oxide and thus appearing as $\mathrm{ABA}$ triblock copolymer. Thermally triggered gelation mechanism of Poloxamer 407 proceeds with initial existence of polymer in the dynamic viscous fluid state at low temperature then formation of a rigid gel matrix which is semisolid in nature as the temperature starts to rise. ${ }^{8}$

Xyloglucan is a mucoadhesive polymer which is quite popular for nasal delivery. It is obtained from seed kernel of Tamarindus indica Linn. (Leguminosae). It is a neutral hemicellulose type of carbohydrate of high molecular weight $(\mathrm{Mw})$. It offers high viscosity, broad $\mathrm{pH}$ tolerance, mucoadhesivity, biocompatibility, in situ gelation and high drug loading capacity.

The bioadhesive properties of Xyloglucan, were evaluated by Kumar et al. in an effort to extent residency in the nasal cavity of Poloxamer 407 in situ gel containing Zolmitriptan, an anti-migraine drug and Ketorolac tromethamine, an anti-inflammatory drug. Results pointed to a significant increase in drugs' bioavailability (21\% for Zolmitriptan and $16 \%$ for Ketorolac tromethamine) after intranasal administration, compared to the oral route. ${ }^{10}$

The present study aims to formulate and characterize in situ nasal gel, which will lead to increased nasal residence time by solving the problem of rapid nasal clearance of administered drug in the conventional nasal formulation and improve bioavailability of Mirtazapine by increasing the absorption through nasal epithelium as compared to oral route. The objectives of the study were to avoid extensive first-pass metabolism, provide rapid drug delivery to the brain, improved therapeutic efficacy and reduce side effects.

\section{MATERIALS AND METHODS}

The pure drug Mirtazapine was obtained as a gift sample from Sun Pharma Advanced Research Center (Vadodara, India). Poloxamer 407 was purchased from Sigma-Aldrich (Mumbai, India). Xyloglucan was gifted by DspGokyo and Chemical Co. Ltd (Japan). Benzalkonium chloride were purchased from Loba Chemie (Nagpur, India). All other reagents used were of analytical grade. Distilled water was used for the study.

Fourier transformed infrared (FTIR) Spectroscopy: FTIR spectroscopy study was carried out to find out the possible interaction between the drug and excipients. Powdered samples of pure Mirtazapine and physical mixture of Mirtazapine with excipients were scanned between 4000 and $400 \mathrm{~cm}^{-1}$ using FTIR spectrophotometer (Model- IR Affinity 1S, Shimadzu, Japan). ${ }^{11}$

Differential Scanning Calorimeter (DSC): DSC measurements were performed on a differential scanning calorimeter (DSC 60 Plus, Shimadzu, Japan) and thermal data obtained were processed using TA60 software System. Inert atmosphere was maintained by purging nitrogen gas at a flow rate of $50 \mathrm{ml} / \mathrm{min}$. Accurately weighed samples of pure Mirtazapine and physical mixture of Mirtazapine with excipients (about 5-10 mg) were placed in a sealed aluminum pan and the samples were heated under nitrogen gas flow $(20 \mathrm{ml} / \mathrm{min})$ at a scanning rate of 10 per min from $40^{\circ} \mathrm{C}$ to $340^{\circ} \mathrm{C}$. An empty aluminum pan was used as reference. ${ }^{11}$

Preparation of in situ Nasal Gel: Three milligrams was fixed for administration into the nostrils. Nasal cavity has a capacity of 4-5 drops per nostrils, $(160-200 \mu \mathrm{L}$ respectively). Therefore the dose of $3 \mathrm{mg}$ was divided as $1.5 \mathrm{mg} / 200 \mu \mathrm{L}$ (or $5 \mathrm{drops}$ ) per nostril.

Poloxamer 407 gel was prepared using cold technique described by Schmolka IR. ${ }^{12}$ Varying amount of Poloxamer 407 (16, 18 and 20\% w/v) was dissolved in cold water with continuous stirring (RQ-122, Remi, India) and kept overnight at $4^{\circ} \mathrm{C}$. Then the Xyloglucan solution as well as Mirtazapine drug solution was added to the above solution and then the final formulation was stored at $4^{\circ} \mathrm{C}$ until further use. The formulation table of nasal gel is shown in Table 1.

Experimental Design: In this work, factorial design was used and optimized for nasal in situ gel using design expert software. Two factors were evaluated for three levels and obtained number of batches were prepared. Randomized full factorial design $\left(3^{2}\right)$ was applied to study the effects of two independent factors on the characteristics of the nasal in situ gel. Two independent variables chosen were concentration of Poloxamer 407 (16-20\%) and Xyloglucan (1-2\%). Dependent variables 


\begin{tabular}{|c|c|c|c|c|c|c|c|c|c|}
\hline \multicolumn{10}{c|}{ Table 1: Composition of the nasal gel formulation. } \\
\hline Ingredients & F1 & F2 & F3 & F4 & F5 & F6 & F7 & F8 & F9 \\
\hline Mirtazapine $(\mathrm{mg})$ & 150 & 150 & 150 & 150 & 150 & 150 & 150 & 150 & 150 \\
\hline Poloxamer $407(\% \mathrm{w} / \mathrm{v})$ & 16 & 16 & 16 & 18 & 18 & 18 & 20 & 20 & 20 \\
\hline Xyloglucan $(\% \mathrm{w} / \mathrm{v})$ & 1 & 1.5 & 2 & 1 & 1.5 & 2 & 1 & 1.5 & 2 \\
\hline Distilled water $(\mathrm{ml})$ & q.s. & q.s. & q.s. & q.s. & q.s. & q.s. & q.s. & q.s. & q.s. \\
\hline
\end{tabular}

Final $10 \mathrm{ml}$ of gel was made for all the nasal formulations

were the viscosity of the solution (cps), mucoadhesive strength (dyne $/ \mathrm{cm}^{2}$ ) and percent cumulative drug permeated after $6 \mathrm{hr}$.

\section{Evaluation parameters of nasal formulation}

Appearance, clarity and pH: Presence or absence of foreign particles in the gel was evaluated by visual inspection method using white and black background. For $\mathrm{pH}$ measurent, calibration was done using digital $\mathrm{pH}$ meter (Elico LI614 pH analyser, India) by using $\mathrm{pH}$ buffer of 4 and 7 . Gel $(20 \mathrm{ml})$ was added in a glass beaker and electrode was immersed in the gel. This procedure was performed in triplicate. ${ }^{13,14}$

Gelling Temperature and Gelation time: Gelation temperature was measured by visual inspection method. Five $\mathrm{ml}$ aliquot of gel was taken in a test tube and placed on a thermostatic water bath (Bio-technics, India). Temperature was raised with increments of $1{ }^{\circ} \mathrm{C}$ and was observed visually for gel formation. Gelling was said to be achieved when the meniscus of gel remained stagnant upon tilting through right angle. Each preparation was tested thrice to control the repeatability of the measurement. The time required for all the liquid to convert completely into gel form at which gelation was observed was termed as gelling time. Gelation time was noted when the transition from liquid to gel started to appear i.e., the time for first detection of gelation. ${ }^{13,15}$

Gel strength determination: Viscosity of the gel determined at nasal physiological $\mathrm{pH}$ is termed as gel strength. Gel was added inside the graduated cylinder and maintained in a thermostatic water bath at $34^{\circ} \mathrm{C}$. Weight of $35 \mathrm{~g}$ was placed upon the gelled solution and the time required for the weight to penetrate a depth of $5 \mathrm{~cm}$ within the gel was recorded. ${ }^{16}$

Drug content: Gel $(0.5 \mathrm{~g})$ was diluted with SNF $\mathrm{pH}$ 5.5 [simulated nasal fluid (SNF) was prepared by dissolving sodium chloride (2.1925 g), calcium chloride $(0.145 \mathrm{~g})$ and potassium chloride $(0.745 \mathrm{~g})$ into $250 \mathrm{ml}$ of double distilled water ${ }^{17}$ and after suitable dilutions, the absorbance was measured at $289 \mathrm{~nm}$ using UV visible spectrophotometer. Further, $\%$ drug content was calculated using the following equation: ${ }^{14}$
$\%$ Drug content $=\frac{\text { Concentration of drug in sample solution }}{\text { Equivalent conc. of drug taken }} \times 100$

Viscosity measurement: The viscosity of nasal formulation was noted at $4^{\circ} \mathrm{C}(\mathrm{sol})$ and $34^{\circ} \mathrm{C}$ (gel) using Synchro-Electric viscometer (RVT, Brookfield, Massachusetts) and spindle number 6 at $100 \mathrm{rpm}$ respectively. ${ }^{18}$

Ex vivo mucoadhesion study: Mucoadhesion study was carried out using modified weighing balance method. Fresh goat nasal mucosal tissue was obtained from local slaughter house for the study. The two pans of the weighing balance were modified as follows: 1) Right pan was for addition of weight and 2) Left pan contained the support for keeping the slide (upper support). Below the upper support of left pan there was another support containing glass slide. Initially the mucosa was fixed on slide of the upper support and moistened with SNF pH 5.5. The gel was sandwiched between the mucosa and was allowed to fix together for few minutes. Then, gradually the weight was added on the right pan until the mucosa separated from each other. The mucoadhesive force $\left(\right.$ dynes $\left./ \mathrm{cm}^{2}\right)$ expressed as the detachment stress in dynes per square centimeter was determined from the minimal weight that detached the mucosal tissue from surface of each formulation.

$$
\text { Mucoadhesive strength }=\frac{\mathrm{g}}{\mathrm{A}} \times \mathrm{m}
$$

Where $\mathrm{m}=$ weight required for detachment in grams, $\mathrm{g}=$ acceleration due to gravity $\left(980 \mathrm{~cm} / \mathrm{s}^{2}\right)$ $\mathrm{A}=$ area of mucosa exposed. ${ }^{15}$

In vitro drug permeation studies: In vitro study was carried using Franz diffusion cell with digital temperature controller (Orchid Scientific, Nashik) having $20 \mathrm{ml}$ capacity. Dialysis membrane-50, LA-393 having cut off molecular weight 12000-14000 kDa (Himedia) was used. Twenty milliliters of SNF pH 5.5 was filled with acceptor chamber calibrated and maintained at $34^{\circ} \mathrm{C}$ and stirring was achieved by means of magnetic stirrer. Then previously soaked dialysis membrane (permeation area of $3.14 \mathrm{~cm}^{2}$ ) was mounted above it. Gel was placed in donor chamber and sampling ( $1 \mathrm{ml}$ volume) 
was done at predetermined time points $(0,30,60,120$, 180, 240, 300, 360, 420 and $480 \mathrm{~min}$ ) and same amount was replenished with SNF pH 5.5. The samples were analyzed using UV spectrophotometer at $289 \mathrm{~nm}$. The kinetics of drug permeation was studied by fitting the data to various kinetic equations (namely zero order, first order, Higuchi and Korsmeyer-Peppas) to determine the appropriate kinetic model. ${ }^{14,15}$

Model validation: Design-Expert ${ }^{\circledR}$ software (Version 12, Stat-Ease Inc., Minneapolis, MN, USA) was utilized to analyze the statistical data for $3^{2}$ full factorial design and to choose an optimized formulation with predetermined characters. ANOVA was used for comparing means at significance level of $\alpha=0.05$.

Ex vivo permeation study (Nasal mucosa): Goat nasal mucosa was utilized for permeation study. The nasal tissue was collected from local slaughter house. Previously nasal tissue was soaked in SNF pH 5.5 and washed three times with SNF pH 5.5 and extraneous tissues were removed. And the same procedure was followed as given in in vitro permeation study. The graph for in vitro and ex vivo results of the optimized batch was constructed between percent cumulative drug permeated versus time. ${ }^{14,15}$

Slopes of the linear portion of graphs were used to calculate the flux (in milligram per hour) and permeability coefficient $(\mathrm{Kp})$ was determined by the following equation:

$$
\mathrm{Kp}=\mathrm{Jss} \times \frac{1}{\mathrm{Cv}}
$$

Where, Jss is steady state flux (in microgram per square centimeter per hour) and $\mathrm{Cv}$ is the total donor concentration of the formulation (in milligram). ${ }^{15}$

\section{Pharmacodynamic study in mice}

All the experimental procedures were approved by the Institutional Animal Ethics Committee (IAEC) of Rashtrasant Tukadoji Maharaj Nagpur University and were in accordance with the Committee for Purpose of Control and Supervision of Experiments on Animals (CPCSEA), Ministry of Social Justice and Empowerment, Government of India.

Procedure: Swiss albino mice weighing 20-23 g were divided into three groups each containing four mice $(\mathrm{N}=12)$. The first group was treated with SNF pH 5.5 given intranasally using micropipette and was considered as control. The second group was treated with marketed Mirtazapine tablet formulation (Mirtaz $7.5 \mathrm{mg}$, Sun Pharma Laboratories Ltd.) in oral solution form containing powder equivalent to $0.0108 \mathrm{mg} / \mathrm{kg}$ given orally using plastic syringe. The third group was treated with optimized formulation equivalent to $0.0108 \mathrm{mg} / \mathrm{kg}$ given intranasally. ${ }^{19}$

Locomotor activity study is a supportive test for forced swim test. It confirms that the results obtained by forced swim test are because of antidepressant effect of drug and not as a result of hyper activity of rats. So by this study, the unbiased results of antidepressant activity can be studied. ${ }^{7-8,20}$

Forced swim test: The post-treatment groups of mice were forced to swim in a vertical plastic cylinder (diameter $21 \mathrm{~cm}$; height $50 \mathrm{~cm}$ ) containing water of up to $25 \mathrm{~cm}$ maintained at $25 \pm 1{ }^{\circ} \mathrm{C}$. On the $1^{\text {st }}$ day of experiments, the mice were forced to swim for $15 \mathrm{~min}$. After $24 \mathrm{hr}$, the mice were re-exposed to forced swim for $5 \mathrm{~min}$ and the onset of immobility and duration of immobility time was evaluated by two observers who were blind to the kind of treatment. A mouse was considered to be immobilized when it was found floating passively in a hunched and upright position with head just above the surface of the water. The test duration was $5 \mathrm{~min}$ and then the animals were kept back into the cage. The total immobility period was expressed in seconds.

Measurement of locomotor activity: Locomotor activity was measured in the open-field test apparatus. The apparatus consisted of a square maze $(100 \times 100 \mathrm{~cm})$, with a $40 \mathrm{~cm}$ height. The floor was divided into 25 equal squares. The test field was sanitized with a $10 \%$ wateralcohol mixture before performing a locomotor test to avoid possible odors and/or residues left by mice tested earlier. The mice were individually placed in the center of the maze and the locomotor activity (number of squares crossed) was measured for $5 \mathrm{~min}$. A square was considered in counting when the mice placed its four paws within the square. All experiments were carried out in a quiet room under controlled light conditions between 10 to $12 \mathrm{hrs}$.

Statistical Analysis: The data of pharmacodynamic study was analyzed by Graph Pad Prism software (Version 5, California, USA) and the statistical comparison of results was performed using one-way ANOVA where appropriate. If any statistically significant change was found, post-hoc comparisons were performed using Dunnett's Multiple Comparison test. Data were considered statistically significant when $p<0.05$.

Histopathological evaluation of goat nasal mucosa: Histopathological evaluation of tissue incubated in SNF pH 5.5 was compared with tissue incubated with optimized nasal gel and IPA (isopropyl alcohol). Tissue was processed by fixing in $10 \%$ buffered formalin $(\mathrm{pH}$ 5.5) and embedded in paraffin. Slides were prepared by cutting sections of $7 \mu \mathrm{m}$ and stained with hematoxylin and eosin. Slides were examined under 
light microscope to evaluate for changes by a pathologist blinded to the study. ${ }^{8}$

Stability studies: Stability study was performed at $40 \pm 2^{\circ} \mathrm{C}$ and $75 \pm 5 \% \mathrm{RH}$ for 1 month. Selected formulation F4 was stored in glass bottle and kept inside the stability chamber (Remi Electrotechnik Ltd., Vasai, India) under specified condition. The viscosity, gel strength, percent drug content and in vitro drug permeation of formulation were evaluated after storage duration of one month. ${ }^{21}$

\section{RESULTS AND DISCUSSION}

FTIR: Figure 1 shows the FTIR spectra of Mirtazapine, physical blend of Mirtazapine and excipients. The FTIR peaks of Mirtazapine were observed at $2966.52 \mathrm{~cm}^{-1}$ for $\mathrm{C}-\mathrm{H}$ aromatic stretch, $1190 \mathrm{~cm}^{-1}$ for $\mathrm{C}-\mathrm{H}$ stretching of benzene ring, at $1585.49 \mathrm{~cm}^{-1}$ for $\mathrm{C}=\mathrm{C}$ aromatic and $1288 \mathrm{~cm}^{-1}$ for C-N group. Both the polymers exhibited compatibility with the drug and also showed the interaction. Poloxamer 407 and Xyloglucan contain carbonyl groups, which were available for interaction with the drug.

DSC: The DSC thermograms of Mirtazapine, physical mixture of Mirtazapine and Xyloglucan and physical mixture of Mirtazapine and Poloxamer 407 were studied (Figure 2). Pure Mirtazapine showed a sharp endothermic peak at $114.29^{\circ} \mathrm{C}$ having an enthalpy of $80.14 \mathrm{~J} / \mathrm{g}$. These results are in accordance with the previous literature. ${ }^{21}$ The melting endotherm of Mirtazapine in presence of Xyloglucan occurred at $113.72^{\circ} \mathrm{C}$ with an enthalpy of $12.68 \mathrm{~J} / \mathrm{g}$ and in presence of Poloxamer 407 occurred at $101.94^{\circ} \mathrm{C}$ with an enthalpy of $10.73 \mathrm{~J} / \mathrm{g}$. In both the cases, there was decrease in the sharpness of the melting peak of Mirtazapine, suggesting the presence of interaction between drug and polymers. The drop in enthalpy in

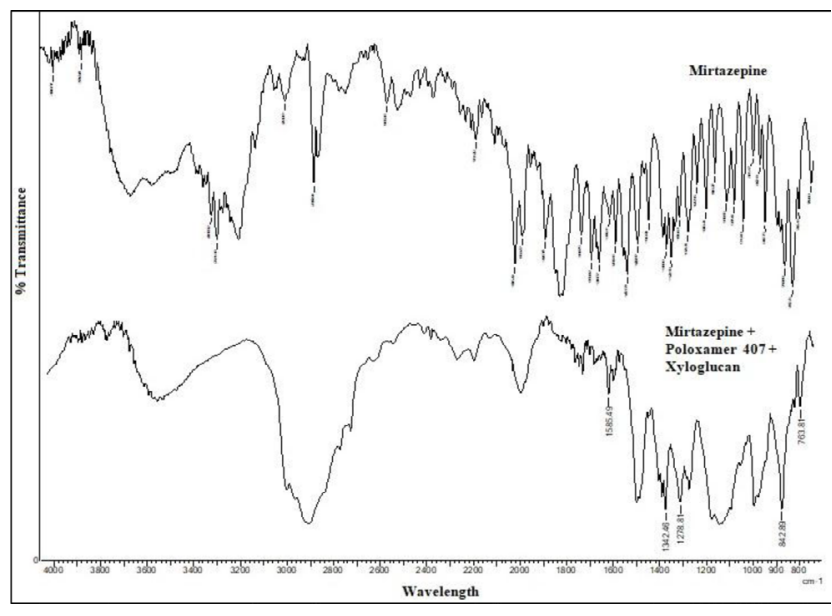

Figure 1: FTIR spectra of Mirtazapine and Mirtazapine physical mixture.

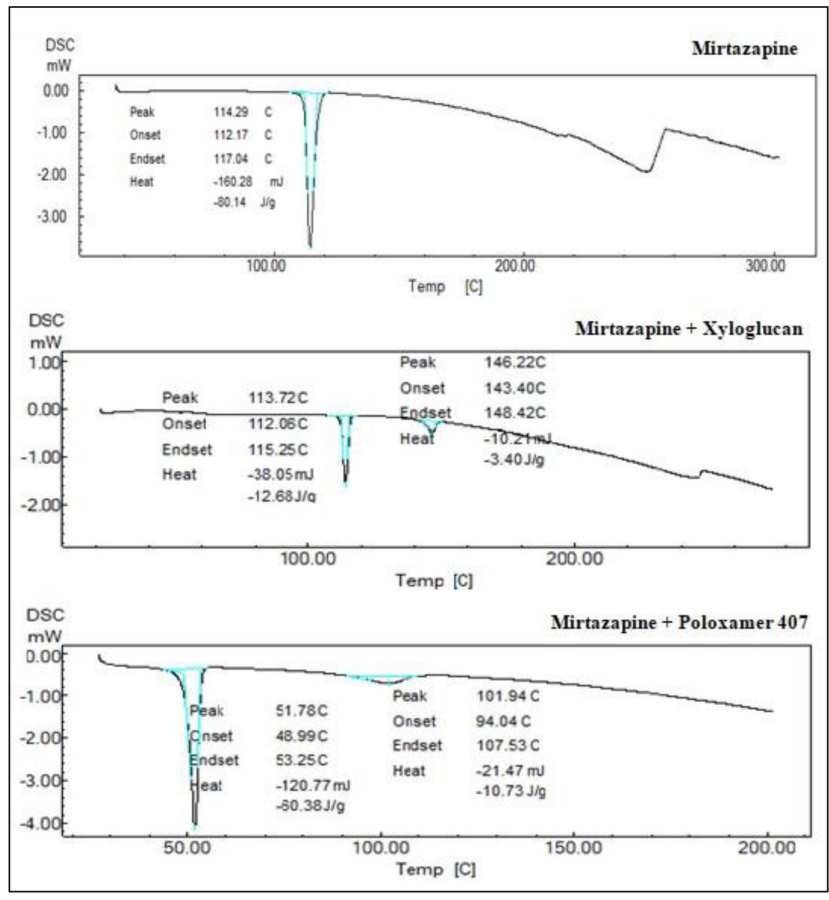

Figure 2: DSC thermogram of Mirtazapine,

Mirtazapine+Xyloglucan and Mirtazapine+Poloxamer 407.

both the cases suggested that there might be interaction that took place place in both the physical mixture. Interactions such as hydrogen bonding may be the possible reason, which can be correlated with the results obtained in the FTIR studies.

\section{Evaluation of in situ nasal gel formulation}

Clarity and $\mathrm{pH}$ : All the prepared gels were clear. The $\mathrm{pH}$ was found to be in the range of 4.5-6.5 for all formulations that were within the nasal physiological $\mathrm{pH}$ range.

Gelation temperature: Gelation temperature for all formulations was found in the range of $30-35^{\circ} \mathrm{C}$ as shown in Table 2. The suitable range of gelling temperature should lie within $25-37^{\circ} \mathrm{C}$. Too high or too low gelling temperature will cause difficulty after nasal administration. A high gelling temperature would result in dripping from nasal tract and vice versa will result in quick gelation before spreading uniformly over the nasal mucosa. The critical micellar temperature of Poloxamer 407 (temperature range of $10-40^{\circ} \mathrm{C}$ ) is closer to physiological temperature of the nasal tract and thus there is aggregation of the polymer molecules to attain the gel structure. Solubility of Mirtazapine in water may have brought modification in the micelle formation of Poloxamer 407 gels resulting in increased gelation temperature. Addition of mucoadhesive polymer Xyloglucan caused lowering of the gelation temperature of the gel. Therefore, Xyloglucan was used along with 


\begin{tabular}{|c|c|c|c|c|c|c|c|}
\hline \multicolumn{7}{|c|}{ Table 2: Evaluation parameters batches F1 to F9. } \\
\hline $\begin{array}{c}\text { Batch } \\
\text { code }\end{array}$ & $\mathbf{p H}$ & $\begin{array}{c}\text { Gelling } \\
\text { temperature } \\
\left({ }^{\circ} \mathbf{C}\right)\end{array}$ & $\begin{array}{c}\text { Gelling Time } \\
(\mathbf{s})\end{array}$ & $\begin{array}{c}\text { Gel Strength } \\
(\mathbf{s})\end{array}$ & $\begin{array}{c}\text { \% Drug } \\
\text { content }\end{array}$ & $\begin{array}{c}\text { Viscosity of sol } \\
\text { (cps) at } 100 \text { rpm }\end{array}$ & $\begin{array}{c}\text { Viscosity of gel } \\
\text { (cps) at 100 rpm }\end{array}$ \\
\hline F1 & $4.9 \pm 0.1$ & $34.97 \pm 1.48$ & $7.47 \pm 0.98$ & $30.36 \pm 1.29$ & $90.29 \pm 1.34$ & $600.33 \pm 0.58$ & $3301.33 \pm 2.31$ \\
\hline F2 & $5.3 \pm 0.2$ & $32.47 \pm 0.47$ & $8.00 \pm 2.00$ & $31.23 \pm 0.94$ & $85.22 \pm 1.03$ & $671.00 \pm 1.00$ & $3351 \pm 1.15$ \\
\hline F3 & $5.1 \pm 0.1$ & $34.13 \pm 1.10$ & $6.67 \pm 1.53$ & $33.24 \pm 2.02$ & $90.67 \pm 0.75$ & $702.00 \pm 1.73$ & $3500.33 \pm 0.58$ \\
\hline F4 & $5.4 \pm 0.1$ & $31.97 \pm 0.55$ & $8.00 \pm 1.00$ & $35.44 \pm 2.63$ & $95.92 \pm 0.95$ & $715.33 \pm 0.58$ & $3680.67 \pm .58$ \\
\hline F5 & $5.2 \pm 0.3$ & $30.80 \pm 0.79$ & $5.67 \pm 0.58$ & $36.82 \pm 1.05$ & $90.90 \pm 1.45$ & $740.67 \pm 1.15$ & $3803.00 \pm .65$ \\
\hline F6 & $5.1 \pm 0.3$ & $31.17 \pm 1.10$ & $9.00 \pm 1.00$ & $37.02 \pm 1.81$ & $92.72 \pm 0.23$ & $712.33 \pm 2.52$ & $3301.67 \pm 1.53$ \\
\hline F7 & $5.3 \pm 0.4$ & $31.50 \pm 0.61$ & $7.00 \pm 1.00$ & $39.97 \pm 0.85$ & $85.30 \pm 1.07$ & $763.00 \pm 2.65$ & $4199 \pm 1.00$ \\
\hline F8 & $5.6 \pm 0.3$ & $31.50 \pm 1.04$ & $8.67 \pm 0.58$ & $40.17 \pm 3.23$ & $93.37 \pm 0.45$ & $800.67 \pm 1.15$ & $4300.67 \pm 1.15$ \\
\hline F9 & $5.1 \pm 0.1$ & $29.80 \pm 1.14$ & $8.33 \pm 1.15$ & $43.53 \pm 1.51$ & $87.47 \pm 1.14$ & $840.33 \pm 0.58$ & $4401.67 \pm 2.08$ \\
\hline
\end{tabular}

Values expressed as mean \pm S.D., $n=3$.

\begin{tabular}{|c|c|c|c|c|c|}
\hline Batch code & $\begin{array}{l}\text { Poloxamer } \\
\left(\% \text { w/v) }\left(X_{1}\right)\right.\end{array}$ & $\underset{\left(X_{2}\right)}{\text { Xyloglucan }(\% w / v)}$ & $\begin{array}{l}\text { Viscosity of sol } \\
\text { (cps) }\left(Y_{1}\right)\end{array}$ & $\begin{array}{l}\text { Mucoadhesive strength } \\
\left(\text { dyne } / \mathrm{cm}^{2}\right)\left(Y_{2}\right)\end{array}$ & $\begin{array}{c}\% \text { Cumulative drug } \\
\text { permeated }\left(\mathrm{Y}_{3}\right)\end{array}$ \\
\hline F1 & 16 & 1 & $600.33 \pm 0.58$ & $6197.00 \pm 0.58$ & 92.24 \\
\hline $\mathrm{F} 2$ & 16 & 1.5 & $671.00 \pm 1.00$ & $6510.33 \pm 0.58$ & 93.46 \\
\hline F3 & 16 & 2 & $702.00 \pm 1.73$ & $6860.33 \pm 1.53$ & 93.41 \\
\hline F4 & 18 & 1 & $715.33 \pm 0.58$ & $7250.33 \pm 2.52$ & 96.51 \\
\hline F5 & 18 & 1.5 & $740.67 \pm 1.15$ & $7360.33 \pm 1.15$ & 91.46 \\
\hline F6 & 18 & 2 & $712.33 \pm 2.52$ & $7840.67 \pm 1.15$ & 92.05 \\
\hline F7 & 20 & 1 & $763.00 \pm 2.65$ & $8398.67 \pm 3.46$ & 93.81 \\
\hline F8 & 20 & 1.5 & $800.67 \pm 1.15$ & $8790.00 \pm 2.15$ & 91.93 \\
\hline F9 & 20 & 2 & $840.33 \pm 0.58$ & $9800.67 \pm 1.15$ & 93.81 \\
\hline
\end{tabular}

Values expressed as mean \pm S.D., $n=3$.

Poloxamer 407 to modify the gelation temperature for causing gelation at appropriate nasal physiological temperature. The results are in accordance with the previous literature. $^{22}$

Gelation time: Gelation time of nasal formulation is given in Table 2.The gelling time of F1, F3, F5 and F7 was within 5-7 s and that of F2, F4, F6, F8 and F9 was within 7-9 s. Optimized formulation F4 was selected as it showed quick gel formation at the nasal physiological temperature with appropriate mucoadhesion.

Gel strength determination: Gel strength duration which is less than $25 \mathrm{~s}$ is reported to not reside inside the nasal cavity and gets removed while gel strength more than $50 \mathrm{~s}$ possess stiffness causing uneasiness to the mucosal surfaces or may cause damage. All formulations showed suitable gel strength as shown in Table 2 . The gel was easy to administer in the nasal cavity and leakage was not observed after administration. Xyloglucan and Poloxamer 407 concentration affected the gel strength in a concentration dependent manner.
Drug content: Drug contents in the nasal gel were found in the range of $85.22-95.92 \%$. It was found that F2 showed least drug content i.e., $85.22 \%$ and F4 showed high drug content i.e., 95.92\%.

Viscosity: Batches F1-F9 had increased viscosity as the concentration of Xyloglucan and Poloxamer 407 increased. Due to the intrinsic property of the Poloxamer 407 to remain in the solution form at low temperature $\left(4^{\circ} \mathrm{C}\right)$, the viscosity was lower than the gel form at higher temperature $\left(34^{\circ} \mathrm{C}\right)$.

Ex vivo mucoadhesion study: The results suggested that increase in the concentration of the Poloxamer 407 increases mucoadhesive strength as shown in Table 3. Higher the values of mucoadhesive strength lesser will be leakage of formulation from the nose, leading to enhanced retention and thus higher absorption across nasal mucosal epithelium. However, excessive mucoadhesive strength (i.e., greater than 10,000 dyne $/ \mathrm{cm}^{2}$ ) of gel can damage the nasal mucosal membrane. ${ }^{15}$ None of the formulations exceeded the upper limit 


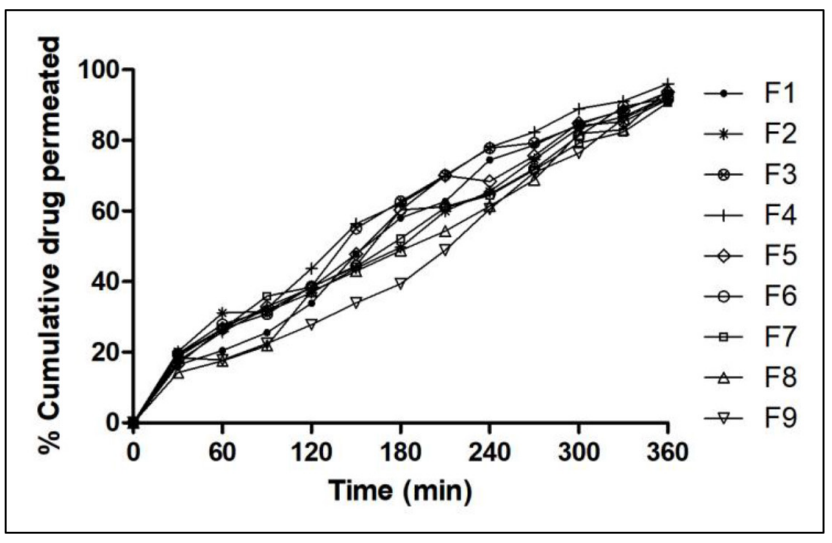

Figure 3: In vitro drug release profile of prepared formulations (F1 to F9).

\begin{tabular}{|}
$\begin{array}{c}\text { Table 4: Release kinetic modelling of optimize in situ } \\
\text { nasal formulation F4. }\end{array}$ \\
\hline Equation & $\boldsymbol{R}^{\mathbf{2}}$ value & $\boldsymbol{n}$ value \\
\hline Zero-order & 0.972 & - \\
\hline First order & 0.964 & - \\
\hline Higuchi & 0.990 & - \\
\hline Korsmeyer-peppas & 0.968 & 0.649 \\
\hline
\end{tabular}

and hence can be visualized as formulations with optimum mucoadhesion properties.

In vitro drug permeation studies: It was concluded from Figure 3 that the polymer concentration affects drug release. All the formulations showed release of the drug for $6 \mathrm{hr}$. As the concentration of Xyloglucan and Poloxamer 407 was increased, drug release pattern of the drug from the formulations F1-F3 decreased and gradually increased in the $\mathrm{F} 4$ formulation and then was decreased upto formulation F9. The data of drug permeation results was fitted into release kinetic models (zero order, first order, Higuchi model and KorsemeyerPeppas model of drug release) as depicted in Table 4. The $R^{2}$ value for Higuchi model was higher for optimized formulation compared to other models. Hence, the in vitro drug release followed Higuchi model of drug release.

\section{Selection of Optimized Formulation}

Statistical analysis of $\mathbf{3}^{2}$ full factorial designs: All 9 formulation batches were developed using two variables as Poloxamer $407\left(\mathrm{X}_{1}\right)$ and Xyloglucan $\left(\mathrm{X}_{2}\right)$ and three responses, viscosity of sol $\left(\mathrm{Y}_{1}\right)$, mucoadhesive strength $\left(\mathrm{Y}_{2}\right)$ and $\%$ cumulative drug permeated $\left(\mathrm{Y}_{3}\right)$ using $3^{2}$ full factorial design. The results of the regression analysis for responses $Y_{1}, Y_{2}$ and $Y_{3}$ were obtained and fit to the linear and quadratic model. The regression equation of the fitted model for the responses were as follows-

$$
\begin{gathered}
\mathrm{Y} 1=727.30+71.78 \mathrm{~A}+29.33 \mathrm{~B} \\
\mathrm{Y} 2=7667.59+1236.95 \mathrm{~A}+442.61 \mathrm{~B} \\
\mathrm{Y} 3=94.55-0.0627 \mathrm{~A}-0.07867 \mathrm{~B}+0.7300 \mathrm{AB}- \\
1.44 \mathrm{~A}^{2}-0.9233 \mathrm{~B}^{2}
\end{gathered}
$$

The quadratic equations for each response were generated as above, where only statistically significant coefficients ( $p=0.0295$ for $\mathrm{Y} 1, p=0.0071$ for $\mathrm{Y} 2, P=0.0138$ for $\mathrm{Y} 3$ ) were included and a positive coefficient indicated that response is favored, while a negative value indicates that the response is unfavorable.

Response Surface Plot: The information obtained from the graph was similar to that obtained from the mathematical equation by statistical analysis. The surface responses plots were obtained after adding the experimentally observed values of viscosity, mucoadhesive strength and \% cumulative drug release for evaluating the effect of independent variables. The concentration of Poloxamer 407 and Xyloglucan at a minimum concentration of 16 to $20 \% \mathrm{w} / \mathrm{v}$ and 1 to $2 \% \mathrm{w} / \mathrm{v}$ respectively increased the viscosity of in situ nasal gel. As the concentration of Xyloglucan was increased, mucoadhesive strength was also increased. A higher concentration of Poloxamer 407 showed the maximum release of the drug while minimum concentrations declined the drug release with time. It was found that $18 \% \mathrm{w} / \mathrm{v}$ of Poloxamer 407 and $1 \% \mathrm{w} / \mathrm{v}$ of Xyloglucan showed the best results. The surface response plots of the the batches are shown in Figure 4.

Optimization of the formulation batch: The numerical optimization technique using desirability was used for optimizing the gel formulation. The constrains included were as follows: concentration of Xyloglucan and Poloxamer 407 were set to target value of $1 \%$ and $18 \%$ respectively, percent drug permeated for $6 \mathrm{hr}$ was set in between value of $91.46-96.51 \%$, viscosity was set to target value of $700 \mathrm{cps}$ and mucoadhesive strength was set to the target value of 7500 dyne $/ \mathrm{cm}^{2}$. The optimized formula consisting of $1 \% \mathrm{w} / \mathrm{v}$ Xyloglucan and

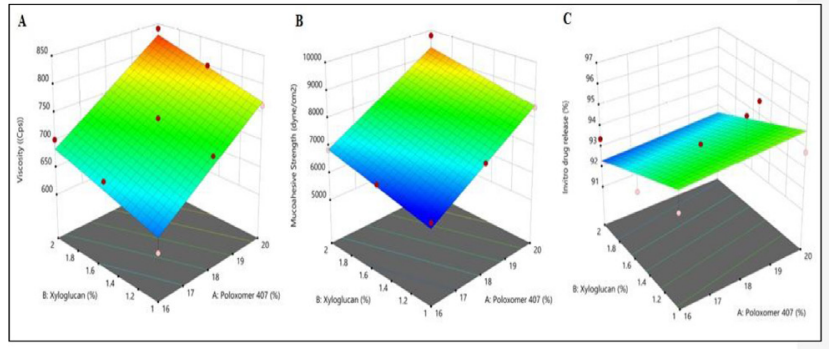

Figure 4: Response surface plot of A) Viscosity, B) Mucoadhesive strength and C) \% Cumulative drug permeated for nasal gel. 


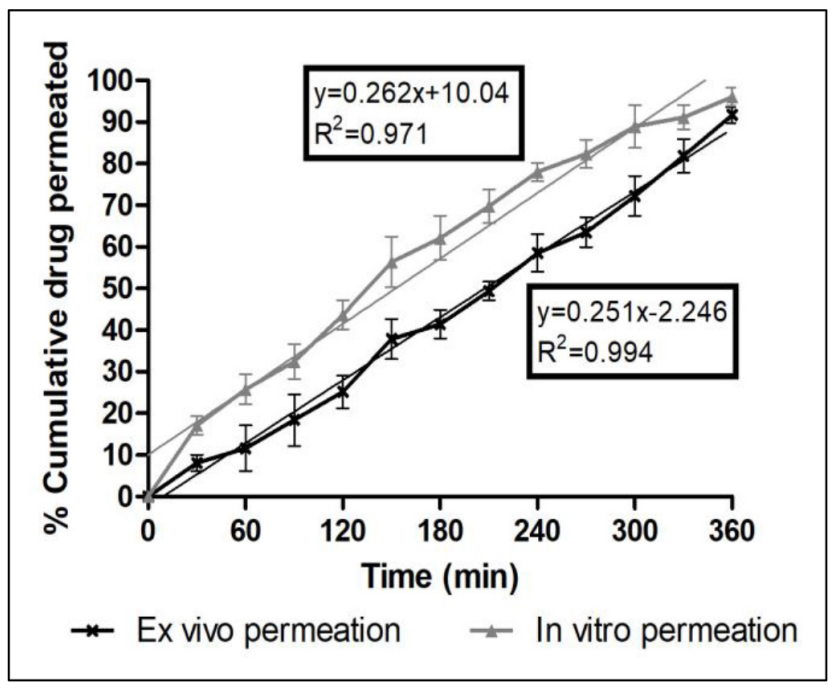

Figure 5: In vitro-ex vivo correlation of formulation F4.

$18 \% \mathrm{w} / \mathrm{v}$ Poloxamer 407 having the desirability of 0.910 was recommended by the design expert software. The observed values for $\%$ cumulative drug permeated for $6 \mathrm{hr}(96.51 \%)$, viscosity $(715.33 \mathrm{cps})$ and mucoadhesive strength $\left(7250.33\right.$ dyne $\left./ \mathrm{cm}^{2}\right)$ were in close agreement with the predicted values for $\%$ cumulative drug permeated at $6 \mathrm{hr}(93.187 \%)$, viscosity $(722.777 \mathrm{cps})$ and mucoadhesive strength $\left(7483.777\right.$ dyne $\left./ \mathrm{cm}^{2}\right)$. Thus, the results confirmed the validity of the predicted model.

Ex vivo permeation study: Formulation F4 was studied for ex vivo permeation using nasal mucosal tissue of goat by Franz diffusion cell. The result of the study showed $91.89 \%$ of drug permeation after $6 \mathrm{hr}$ of study as shown in Figure 5. Flux was evaluated for the comparative study. The steady state flux calculated for in vitro permeation and for ex vivo permeation was found to be 1.965 and $1.8825 \mu \mathrm{g} \mathrm{cm}^{-2} \mathrm{~h}^{-1}$ respectively.

\section{Pharmacodynamic study}

Pharmacodynamic activity was performed in mice for nasal in situ gel formulation and was compared with orally administered dose. Immobility period of control group, orally treated group and gel-treated group was compared. Decrease in time of immobility would result in high concentration of Mirtazapine reaching to the brain.

Forced swim test: One way ANOVA was applied to the data of treatment groups of the forced swim test and significant difference with $p<0.05$ was observed between the treatment groups. The post-hoc Dunnett's test as shown in Table 5 confirmed the significant difference. The nasal gel was more effective in reducing the total immobility period as shown in Figure 6.

\begin{tabular}{|c|c|c|}
\hline \multicolumn{3}{|c|}{ Table 5: Dunnett's Multiple Comparison test on } \\
forced swim test. \\
\hline Compared groups & $\begin{array}{c}\text { Mean } \\
\text { Difference }\end{array}$ & $\begin{array}{c}\text { Significant? } \\
p<0.05 ?\end{array}$ \\
\hline $\begin{array}{c}\text { Control group vs. } \\
\text { Mirtazapine tablet }\end{array}$ & 37.6 & Yes \\
\hline $\begin{array}{c}\text { Control group vs. in situ } \\
\text { nasal gel (F4) }\end{array}$ & 72.2 & Yes \\
\hline
\end{tabular}

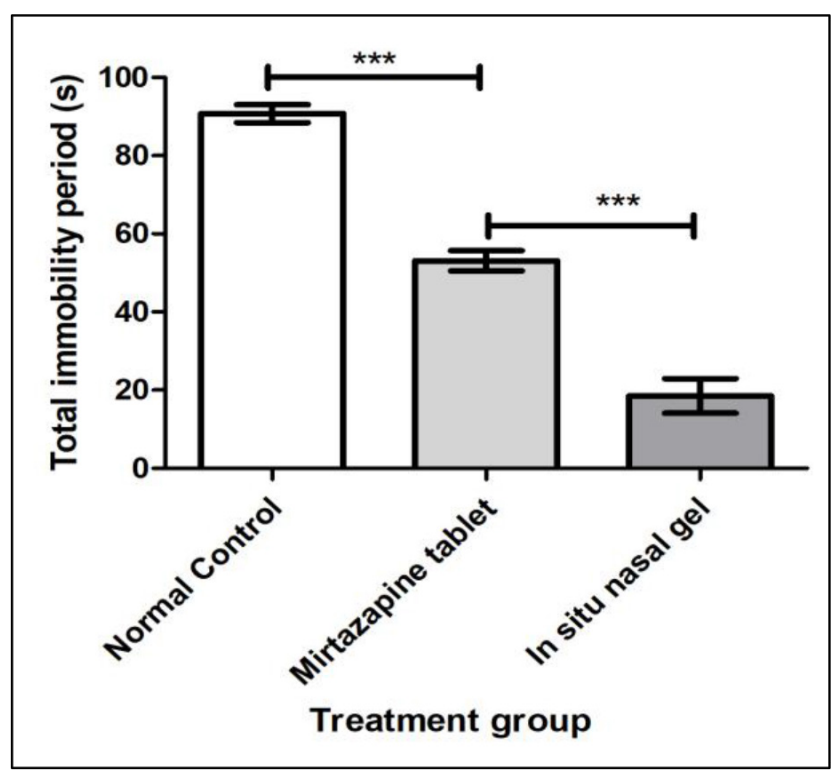

Figure 6: Forced swim test.

\section{Table 6: Measurement of locomotor Activity.}

\begin{tabular}{|c|c|c|c|c|c|}
\hline Treatment group & \multicolumn{4}{|c|}{$\begin{array}{c}\text { Number of squares } \\
\text { crossed }\end{array}$} & Mean \\
\hline Control & 90 & 57 & 78 & 34 & $64.75 \pm 24.62$ \\
\hline Mirtazapine tablet & 85 & 63 & 77 & 52 & $69.25 \pm 14.66$ \\
\hline In situ nasal gel (F4) & 83 & 77 & 81 & 60 & $75.25 \pm 10.47$ \\
\hline
\end{tabular}

$p>0.05(p=0.7087)$ Mean significantly different - No

Measurement of locomotor activity in mice: The animal when moves from one quadrant to another quadrant with all four paws placed in a single square then it is termed as complete locomotion. The locomotion is measured as total number of squares covered by the animal while movement. One way ANOVA was applied to the data of locomotor activity of mice including control, orally treated and in situ nasal gel-treated group and the results were found to be statistically nonsignificant as shown in Table 6. The results of the study revealed the enhanced antidepressant activity of Mirtazapine gel by nasal route as compared to oral route of administration. It may be concluded that maximum amount of drug reached the brain efficiently through 


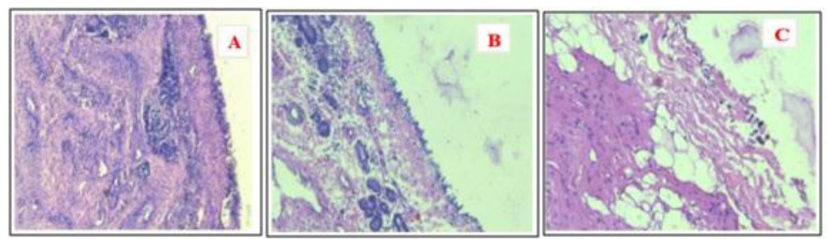

Figure 7: Histopathology of goat nasal mucosa A) Mirtazapine gel F4, B) SNF $5.5 \mathrm{pH}$ (negative control) and C) IPA (positive control).

\begin{tabular}{|c|c|c|c|}
\hline \multirow{2}{*}{$\begin{array}{l}\text { Sr. } \\
\text { No. }\end{array}$} & \multirow[t]{2}{*}{ Parameter } & \multicolumn{2}{|c|}{$\begin{array}{l}\text { Storage period } 1 \text { month at } \\
40 \pm 2^{\circ} \mathrm{C} \text { and } 75 \pm 5 \% \mathrm{RH}\end{array}$} \\
\hline & & Initial & After 1 month \\
\hline 1 & Viscosity (cps) & $715.33 \pm 0.58$ & $714.63 \pm 0.34$ \\
\hline 2 & $\begin{array}{c}\text { Mucoadhesive } \\
\text { strength (dyne/cm²) }\end{array}$ & $7250.33 \pm 2.52$ & $7259 \pm 1.82$ \\
\hline 3 & Drug content (\%) & $95.92 \%$ & $94.34 \%$ \\
\hline 4 & $\begin{array}{l}\text { Cumulative drug } \\
\text { permeated }(\%)\end{array}$ & $96.07 \%$ & $95.67 \%$ \\
\hline
\end{tabular}

Values expressed as mean \pm S.D., $n=3$.

nasal epithelium bypassing the first pass metabolism in comparison to oral administration of tablet. This was indicated by reduction in total immobility period.

Histopathological evaluation of goat nasal mucosa: From the Figure 7, A) Mirtazapine gel F4 showed intact nasal mucosa, epithelium, goblet and basal cells. In B) SNF $5.5 \mathrm{pH}$ (negative control) there was also intact nasal mucosa and epithelium layer but C) IPA (positive control) treated mucosa was damaged removal of nasal epithelium layer, destruction of basal, goblet cells and disappearance of the mucosal layer. Histopathological study suggested that the nasal in situ gel formulation was non-toxic and proved safer to administer.

Stability studies: One month stability of optimized batch F4 was performed. The gel remained stable for specified duration with insignificant changes in viscosity, gel strength, drug content and in vitro drug permeated as shown in Table 7.

\section{CONCLUSION}

Thermosensitive in situ nasal gel was prepared using Poloxamer 407 (18\%) due to its uniqueness in gelation at temperature similar to the physiological temperature. Xyloglucan was used to impart mucoadhesiveness in variable concentrations. The formulations were evaluated for mucoadhesive strength, gel strength, viscosity, drug content, in vitro and ex vivo drug permeation. The gel was easy to administer in the nasal cavity due to the rheological property which enabled to remain sol at ambient temperature $\left(25^{\circ} \mathrm{C}\right)$ and get transformed to gel structure at nasal physiological temperature. The histopathological studies resulted in safety of gel formulation for administration. Pharmacodynamic activity in mice resulted in improvement in therapeutic efficacy using forced swim test and locomotor activity. Thus, the present study endeavors the possibility of formulating Mirtazapine nasal gel bypassing the extensive hepatic metabolism through oral route.

\section{ACKNOWLEDGEMENT}

The authors are thankful to Sun Pharma Advanced Research Center (Vadodara, India) and DspGokyo and Chemical Co. Ltd (Japan) for their generous gift sample of Mirtazapine and Xyloglucan respectively.

\section{CONFLICT OF INTEREST}

Authors declare no conflict of interest.

\section{ABBREVIATIONS}

FTIR: Fourier Transform Infrared; DSC: Differential scanning calorimetry; SNF: Simulated nasal fluid.

\section{REFERENCES}

1. Iyer K, Khan Z. Depression: A Review. Res J Recent Sci. 2012;1(4):79-87.

2. Depression Guideline Panel. Depression in Primary Care: Detection, Diagnosis and Treatment. Journal of the American Academy of Nurse Practitioners. 1994;6(5):224-38.

3. Marcus M, Yasamy MT, Ommeren MV, Chisholm D. Depression, a global public health concern. WHO Dep Ment Heal Subst Abus. 2012;1-8.

4. Löscher W, Potschka H. Role of drug efflux transporters in the brain for drug disposition and treatment of brain diseases. Prog Neurobiol. 2005;76(1):22-76.

5. Misra A, Ganesh S, Shahiwala A, Shah SP. Drug delivery to the central nervous system: A review. J Pharm Pharm Sci. 2003;6(2):252-73.

6. Illum L. Nasal drug delivery: Possibilities, problems and solutions. J Control Release. 2003;87(1-3):187-98.

7. Thakkar HP, Patel AA, Chauhan NP. Intranasal mucoadhesive microemulsion of mirtazapine: Pharmacokinetic and pharmacodynamic studies. Asian $\mathrm{J}$ Pharm. 2013;7(1):36-42.

8. Bhandwalkar MJ, Avachat AM. Thermoreversible nasal in situ gel of venlafaxine hydrochloride: Formulation, characterization and pharmacodynamic evaluation. AAPS Pharm Sci Tech. 2013;14(1):101-10.

9. Pardeshi CV, Kulkarni AD, Belgamwar VS, Surana SJ. Xyloglucan for drug delivery applications. Fundamental Biomaterials: Polymers. Elsevier Ltd. 2018;143-69.

10. Kumar A, Garg T, Sarma GS, Rath G, Goyal AK. Optimization of combinational intranasal drug delivery system for the management of migraine by using statistical design. Eur J Pharm Sci. 2015;70(2):140-51.

11. Wadetwar RN, Charde T. Design, development and characterization of oromucosal wafer of Tramadol Hydrochloride. Asian J Pharm Clin Res. 2018;11(8):116-22.

12. Schmolka IR. Artificial skin I. Preparation and properties of pluronic F-127 gels for treatment of burns. J Biomed Mater Res. 1972;6(6):571-82.

13. Pandit AP, Pol VV, Kulkarni VS. Xyloglucan Based in situ Gel of Lidocaine $\mathrm{HCl}$ for the Treatment of Periodontosis. J Pharm. 2016;1-9.

14. Jagdale S, Shewale N, Kuchekar BS. Optimization of Thermoreversible in situ Nasal Gel of Timolol Maleate. Scientifica. 2016;1-11. 
15. Singh RMP, Kumar A, Pathak K. Thermally triggered mucoadhesive in situ gel of loratadine: $\beta$-Cyclodextrin complex for nasal delivery. AAPS Pharm Sci Tech. 2013;14(1):412-24.

16. Viram P, Lumbhani AN. Development and evaluation of ion- dependent in- situ nasal gelling systems of metoclopramide hydrochloride as an antimigraine model drug. Int J Latest Research Sci Technol. 2012;1(2):80-9.

17. Galgatte UC, Kumbhar AB, Chaudhari PD. Development of in situ gel for nasal delivery: Design, Optimization, in vitro and in vivo Evaluation. Drug Deliv. 2014;21(1):62-73.

18. Sherje AP, Londhe V. Development and Evaluation of $\mathrm{pH}$-Responsive Cyclodextrin-Based in situ Gel of Paliperidone for Intranasal Delivery. AAPS Pharm Sci Tech. 2018;19(1):3840-94.
19. Nair A, Jacob S. A simple practice guide for dose conversion between animals and human. J Basic Clin Pharm. 2016;7(2):27.

20. Rogóz Z. Effects of co-treatment with mirtazapine and low doses of risperidone on immobility time in the forced swimming test in mice. Pharmacol Reports. 2010;62(6):1191-6.

21. Koradia H, Chaudhari K. Formulation of unidirectional buccal tablet of Mirtazapine: An in vitro and ex vivo evaluation. J Drug Deliv Sci Technol. 2018;43:233-42.

22. Wang $\mathrm{Y}$, Jiang $\mathrm{S}$, Wang $\mathrm{H}$, Bie $\mathrm{H}$. A mucoadhesive, thermoreversible in situ nasal gel of geniposide for neurodegenerative diseases. PLoS One. 2017;12(12):1-17.

\section{SUMMARY}

Mirtazapine nasal in situ gel was formulated and evaluated for the treatment of depression. Normal gel would be wiped out easily due to the self-cleansing action of the nasal ciliary mucosa and with an effort to enhance the residence time inside the nasal cavity, in situ nasal gel was formulated. To make the formulation mucoadhesive, Xyloglucan and Poloxamer 407 was used which allowed the mucoadhesive and in situ gelling property inside the nasal tract at the nasal physiological temperature. The design expert software was used to design the batches using $3^{2}$ full factorial design. The FTIR, DSC studies were carried out which revealed that the drug and excipients were compatible. All the prepared batches were within the range of nasal $\mathrm{pH}$. The optimized batch was concluded to be F4 with mucoadhesive strength of 7250.33 dyne $/ \mathrm{cm}^{2}$, viscosity of $715.33 \pm 0.58$ cps and in vitro cumulative drug permeation of $91.89 \%$ respectively. The in vitro and ex vivo flux was found to be 1.965 and $1.8825 \mu \mathrm{g} \mathrm{cm}^{-2} \mathrm{~h}^{-1}$ respectively. The histopathological studies revealed non toxicity of gel to nasal mucosa. The pharmacodynamic study was carried out using force swim test using mice model. The nasal gel showed high efficacy than oral marketed tablet in mice. The first pass effect is bypassed when Mirtazapine is given through nasal route and thus dose can be reduced. The nasal in situ gel can be promising in the treatment of depression.

\section{PICTORIAL ABSTRACT}



\section{About Authors}

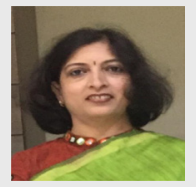

Rita Naresh Wadetwar, She is currently working as assistant professor at Department of Pharmaceutical Sciences, Rashtrasant Tukadoji Maharaj Nagpur University.



Vaibhav Dilip Deshmukh, He is currently working in Aleor Dermaceuticals, Hyderabad as Research Associate.

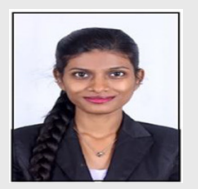

Pranita Sunil Kanojiya, She is a $\mathrm{PhD}$ research scholar at Department of Pharmaceutical Sciences, Rashtrasant Tukadoji Maharaj Nagpur University. Qualified CSIR NET (Life Sciences) and GATE.

Cite this article: Wadetwar RN, Deshmukh VD, Kanojiya PS. Xyloglucan Based Nasal in situ Gel Formulation of Mirtazapine for Treatment of Depression. Indian J of Pharmaceutical Education and Research. 2020;54(2s):s210-s219. 